\title{
Pembakaran Bersama Biomassa dan Batu Bara: Pengaruh Rasio Biomassa-Batu Bara dan Excess Air
}

\author{
Heru Sutarto $^{1}$, Tito Gusti Nurrohim ${ }^{1}$, Albert Xaverio Ilyas ${ }^{1}$, Suyitno $^{\mathbf{1}^{*}}$ \\ ${ }^{* 1}$ Fakultas Teknik, Universitas Sebelas Maret \\ e-mail address : suyitno@uns.ac.id
}

\begin{tabular}{|c|c|}
\hline Keywords: & Abstrak: \\
\hline $\begin{array}{l}\text { Biomassa, Batu bara, } \\
\text { Pembakaran Bersama, } \\
\text { Perbandingan Udara Bahan } \\
\text { Bakar. }\end{array}$ & $\begin{array}{l}\text { Pemanfaatan batu bara dan biomassa untuk menghasilkan panas dan daya } \\
\text { semakin meningkat seiring dengan kebutuhan energi yang semakin tinggi. } \\
\text { Cadangan batu bara Indonesia yang sebagian besarnya adalah batu bara } \\
\text { kualitas rendah, menarik untuk diteliti bersamaan dengan pemanfaatan } \\
\text { biomassa. Sehingga tujuan dari studi ini adalah melakukan investigasi } \\
\text { pengaruh perbandingan udara bahan bakar suatu tungku pembakaran bersama } \\
\text { antara biomassa dan batu bara. Penelitian dilakukan secara simulasi computer } \\
\text { menggunakan perangkat lunak ASPEN PLUS. Hasil dari penelitian } \\
\text { menunjukkan pemodelan termodinamika dengan ASPEN PLUS mampu } \\
\text { menyimulasikan pembakaran bersama antara biomassa dan batu bara. } \\
\text { Penambahan biomassa menurunkan temperatur gas pembakaran dari } 900^{\circ} \mathrm{C} \\
\text { menjadi } 400^{\circ} \mathrm{C} \text { sehingga menurunkan kadar NOx dan SOx. Pengaruh excess } \\
\text { air menurunkan temperatur pembakaran. Efisiensi tungku pembakaran } \\
\text { bersama antara biomassa dan batu bara diatas } 60 \% \text { dan dipengaruhi oleh } \\
\text { komposisi campuran. }\end{array}$ \\
\hline
\end{tabular}

\section{PENDAHULUAN}

Pembakaran atau oksidasi merupakan proses reaksi kimia antara bahan bakar dengan oksidator yang menghasilkan panas yang diperlukan untuk kebutuhan sehari-hari. Reaksi kimia pada proses oksidasi umumnya adalah reaksi eksoterm. Proses pembakaran biomassa dan batu bara termasuk reaksi kimia yang kompleks dimana unsur-unsur pembentuk dari biomassa dan batu bara bereaksi dengan oksigen [1]. Dari analisis ultimate dan proximate, dapat diketahui bahwa kandungan dari unsur-unsur pembentuk batu bara dan biomassa sangatlah berbeda, sehingga juga mempunyai nilai kalor yang berbeda. Penelitian tentang pembakaran bersama antara batu bara dan biomassa menjadi topik menarik dari berbagai peneliti terbukti setiap tahun rata-rata terdapat publikasi sebanyak 1100 artikel pada google scholar.

Penelitian secara eksperimen telah dilakukan pada campuran biomassa batu bara yang mengandung $10 \%, 20 \%$, dan $30 \%$ berat pelet biomassa. Peningkatan konten biomassa dalam campuran mampu menurunkan kadar NO dan $\mathrm{NO}_{2}$. Tidak ada korelasi yang jelas antara emisi partikel (PM) dan konten biomassa dalam campuran yang diamati [2]. Studi eksperimen tentang pembakaran bersama antara batu bara bituminous dengan kayu telah dilakukan sampai penambahan biomassa sebanyak $40 \%$. Perubahan emisi gas buang tidak drastis dan penggunaan campuran biomassa sampai $40 \%$ dengan batu bara dapat menjadi alternatif sumber bahan bakar untuk combustor [3].

Selain penelitian eksperimen, terdapat juga penelitian menggunakan simulasi CFD ANSYS untuk pembakaran bersama antara batu bara dan biomassa [4]. Keuntungan nyata dari penambahan biomassa pada pembakaran batu bara adalah terdapatnya volatile dalam jumlah yang banyak yang mampu meningkatkan tingkat penyalaan.

Sementara itu, kualitas pembakaran sangat dipengaruhi oleh jumlah udara dan jumlah bahan bakar yang masuk ke ruang bakar. Besaran ini diwakili dengan AFR (air fuel ratio). Untuk pembakaran sempurna memerlukan sejumlah udara yang cukup yang disebut dengan AFR stoikiometri, sehingga seluruh unsur bahan bakar

https://dx.doi.org/10.20961/mekanika.v19i1.40039 
akan berubah menjadi gas $\mathrm{CO}_{2}$ dan $\mathrm{H}_{2} \mathrm{O}$ tanpa ada bahan bakar yang tersisa [5]. Udara berlebih seringkali juga diperlukan untuk menyempurnakan pembakaran. Dengan demikian, kualitas pembakaran dan kualitas gas hasil pembakaran sangat dipengaruhi oleh AFR. Sayangnya, masih terbatas penelitian yang membahas pengaruh AFR pada kualitas pembakaran dan kualitas gas hasil pembakaran camuran biomassa dan batu bara khususnya menggunakan pemodelan termodinamika.

Tujuan dari penelitian adalah validasi model termodinamika pembakaran bersama antara biomassa dan udara. Tujuan lainnya adalah melihat pengaruh excess air pada kualitas pembakaran dan kualitas gas buang hasil pembakaran.

\section{METODOLOGI PENELITIAN}

Bahan yang digunakan adalah biomassa dan batu bara dengan spesifikasi dapat dilihat pada Tabel 1. Analisis proksimat dilakukan untuk mengetahui kadar air, volatile, karbon tetap, dan abu. Analisis ultimate dilakukan untuk mengetahui unsur penyusun batu bara dan biomassa seperti carbon, hidrogen, oksigen, nitrogen, sulfur, dan klorin. Kadar ultimat dan proksimat biomassa dan batu bara ini dalam pemodelan diimplementasikan ke dalam padatan non conventional (NC) [6]. Besarnya laju biomassa dan batu bara dijaga konstan sebesar 14 $\mathrm{kg} / \mathrm{h}$ [7].

Tabel 1. Spesifikasi batu bara dan biomassa [7]

\begin{tabular}{|c|c|c|c|c|c|}
\hline \multirow{2}{*}{$\begin{array}{l}\text { Bahan } \\
\text { Baku }\end{array}$} & \multicolumn{4}{|c|}{ Proximate $(\%)$} & \multirow{2}{*}{$\begin{array}{c}\text { HHV } \\
(\mathrm{MJ} / \mathrm{kg})\end{array}$} \\
\hline & $\begin{array}{c}\text { Kadar } \\
\text { Air }\end{array}$ & Volatil & $\begin{array}{c}\text { Karbon } \\
\text { Tetap }\end{array}$ & Abu & \\
\hline Biomassa & 8,4 & 65,5 & 13,7 & 12,4 & 13,2 \\
\hline Batu bara & 12,7 & 47,8 & 27,4 & 12,1 & 20,9 \\
\hline Bahan & \multicolumn{5}{|c|}{ Ultimate } \\
\hline Baku & Karbon & Hidrogen & Oksigen & Nitrogen & Sulfur \\
\hline Biomassa & 36,9 & 5,2 & 43,7 & 0,5 & 0,1 \\
\hline Batu bara & 66,2 & 6,1 & 12,3 & 1,0 & 0,6 \\
\hline
\end{tabular}

Untuk pemodelan pembakaran dapat dilakukan melalui tiga tahap. Tahap pertama adalah tahap pengeringan, dimana kadar air dalam biomassa maupun batu bara dikeluarkan. Pada pemodelan ASPEN, proses pengeringan menggunakan reaktor stiokiometri dengan mengikuti persamaan:

Biomassa Basah $\rightarrow \alpha \mathrm{H}_{2} \mathrm{O}+$ Biomassa kering (1)

Batu bara Basah $\rightarrow \alpha \mathrm{H}_{2} \mathrm{O}+$ Batu bara kering (2)

Dimana $\alpha$ adalah koefisien reaksi $\mathrm{H}_{2} \mathrm{O}$ yaitu 0,0555084 dan besarnya panas reaksi adalah 43,9 $\mathrm{kJ} / \mathrm{mol}$.

Tahap kedua dari pembakaran adalah devolatilisasi, dimana unsur batu bara dan biomassa selain abu dikonversi menjadi gas. Pemodelan devolatilisasi menggunakan reactor RYield yang dilengkapi dengan kalkulator konversi. Penggunaan RYield untuk pemodelan devolatilisasi lebih sederhana dibandingkan dengan pemodelan devolatilisasi menggunakan reaksi kinetik [8-11]. Tahap ketiga adalah pembakaran gas yang dimodelkan di dalam reactor RGibbs. Pada studi sebelumnya, RGibbs mampu menyimulasikan pembakaran biogas dengan baik [12]. Selanjutnya, energi panas yang dihasilkan oleh RGibbs sebagiannya digunakan untuk memanaskan reactor pengeringan dan reactor pirolisis.

Pembakaran bersama antara biomassa dan batu bara dilakukan pada berbagai variasi laju biomassa dan batu bara dimana jumlah total bahan baku yang masuk sebesar $14 \mathrm{~kg} / \mathrm{jam}$. Sedangkan udara yang masuk divariasikan dari excess air 0\%, 10\%, 20\%, dan 30\%. Parameter yang diamati adalah perubahan temperatur gas buang, kadar gas-gas penyusun dalam gas buang, dan efisiensi pembakaran. Adapun efisiensi pembakaran dihitung dengan rumus:

Efisiensi pembakaran $=$

laju gas hasil $\mathrm{x}$ nilai kalor gas hasil

laju bahan bakar masuk x nilai kalor bahan bakar masuk

\section{HASIL DAN PEMBAHASAN}

\subsection{Validasi Model}

Simulasi model termodinamika pembakaran bersama antara biomassa dengan batu bara dilakukan menggunakan ASPEN PLUS. Model ini dilakukan validasi dengan hasil eksperimen 
yang dilakukan oleh Unchaisri [7] pada pembakaran bersama dengan circulating fluidized bed. Hasil perbandingan antara simulasi dan eksperimen difokuskan pada temperatur dan gas hasil pembakaran sebagaimana dapat dilihat pada Tabel 2.

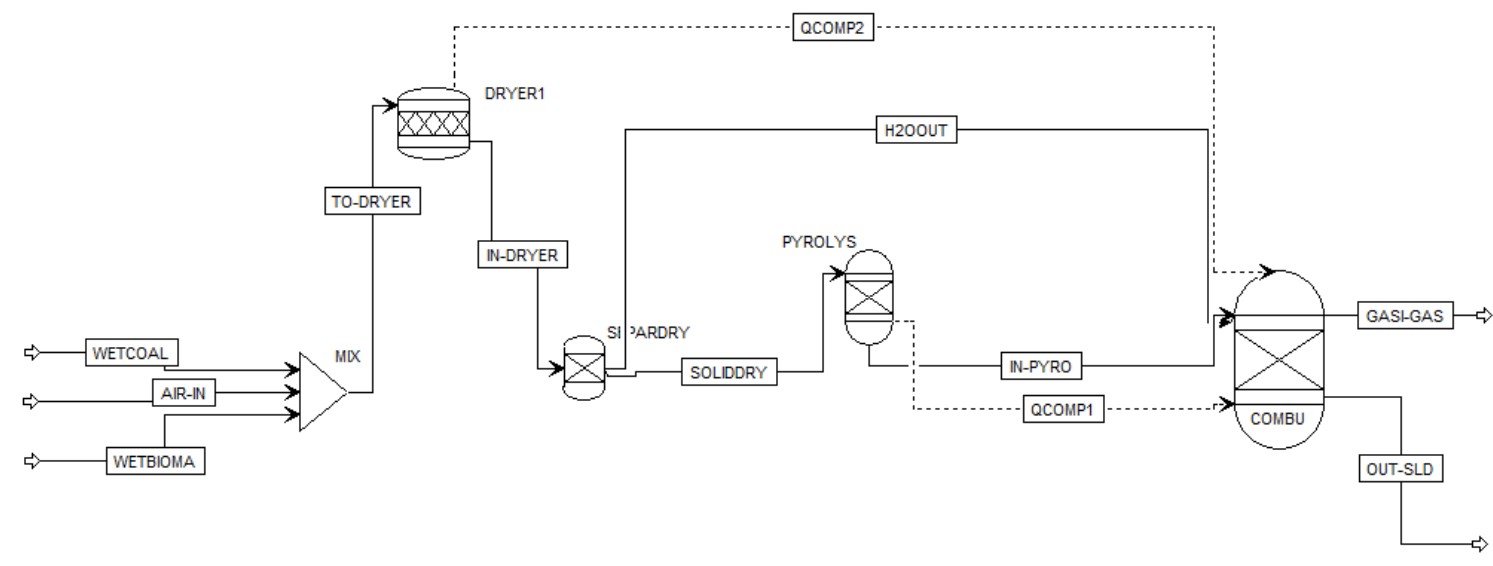

Gambar 1. Skema pemodelan pembakaran bersama biomassa dan batu bara dalam ASPEN PLUS

Tabel 2. Validasi hasil simulasi dengan eksperimen

\begin{tabular}{|l|c|c|c|c|}
\hline Parameter & $\begin{array}{c}\text { Temperatur } \\
\text { pembakaran }\end{array}$ & $\begin{array}{c}\mathrm{CO} \\
(\mathrm{ppm})\end{array}$ & $\begin{array}{c}\mathrm{NOx} \\
(\mathrm{ppm})\end{array}$ & $\begin{array}{c}\mathrm{SO}_{2} \\
(\mathrm{ppm})\end{array}$ \\
\hline Simulasi & $687^{\circ} \mathrm{C}$ & 3468 & 11.121 & 221 \\
\hline Eksperimen & $650-690^{\circ} \mathrm{C}$ & 3403 & 100 & 110 \\
\hline
\end{tabular}

Terlihat bahwa model pembakaran bersama antara batu bara dan biomassa cukup valid yang ditandai dengan nilai berbagai parameter yang dekat dengan hasil eksperimen. Temperatur pemodelan sebesar $687^{\circ} \mathrm{C}$ berada dalam jangkauan temperatur hasil pembakaran sebesar $650-690^{\circ} \mathrm{C}$. Konsentrasi CO antara hasil simulasi dengan hasil pembakaran juga cukup dekat nilainya. Pada $\mathrm{NOx}$ dan $\mathrm{SO}_{2}$, hasil simulasi lebih tinggi dibandingkan dengan hasil dari eksperimen yang menunjukkan bahwa RGibbs cenderung menghasilkan kadar $\mathrm{NOx}$ dan $\mathrm{SO}_{2}$ yang lebih tinggi karena temperatur yang dihasilkan juga cenderung lebih tinggi dibandingkan dengan eksperimen.

\subsection{Pengaruh Perbandingan Biomassa/Batu bara dan Excess Air}

Temperatur gas hasil pembakaran sangat dipengaruhi oleh komposisi biomassa dan batu bara. Batu bara yang mempunyai kandungan karbon lebih tinggi dan juga mempunyai nilai kalor lebih tinggi menghasilkan gas dengan temperatur sampai mendekati $900^{\circ} \mathrm{C}$. Hasil ini sejalan dengan penelitian eksperimental sebelumnya yang menyatakan bahwa temperatur tertinggi yang mampu dicapai pada pembakaran temperatur penyalaan dan temperatur akhir gas pembakaran karena volatile lebih mudah menyala dan terbakar lebih cepat dibandingkan karbon [14].

Gambar 3, 4, dan 5 menunjukkan komposisi gas hasil pembakaran campuran biomassa dan batu bara. Seiring dengan bertambahnya biomassa dalam campuran menyebabkan kadar $\mathrm{CO}_{2}$ menurun, kadar $\mathrm{O}_{2}$ meningkat sedangkan kadar $\mathrm{H}_{2} \mathrm{O}$ cenderung tetap. Penyebabnya adalah karena biomassa yang mempunyai kandungan oksigen lebih tinggi.

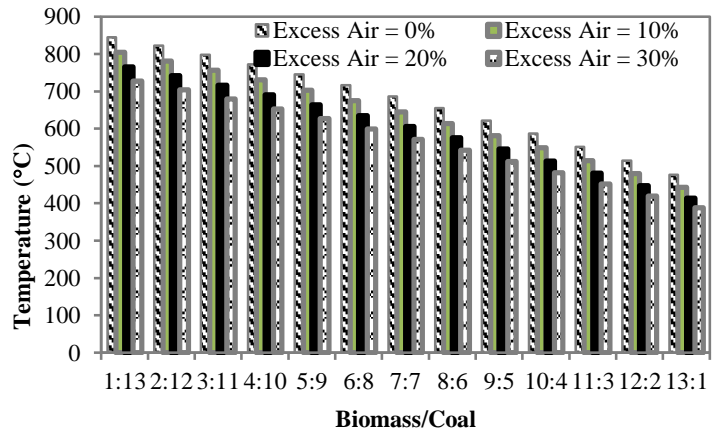

Gambar 2. Temperatur gas hasil pembakaran campuran biomassa dan batu bara. 


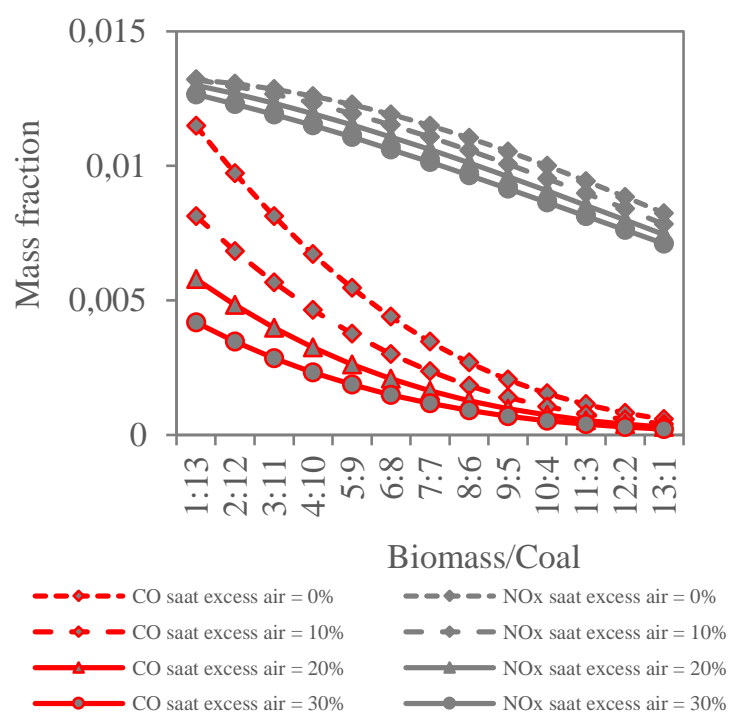

Gambar 3. Komposisi CO dan NOx dalam gas hasil pembakaran

Komposisi gas $\mathrm{CO}, \mathrm{NOx}, \mathrm{H}_{2}$, dan $\mathrm{SOx}$ cenderung mengalami penurunan seiring dengan bertambahnya biomassa dalam campuran. Laju penurunan $\mathrm{CO}$ lebih besar dibandingkan dengan laju penurunan NOx. Besarnya kadar $\mathrm{CO}$ dalam gas pembakaran adalah 0,7-1,3\%. Pengaruh excess air mampu menurunkan kadar $\mathrm{CO}$ dalam gas buang. Hal ini sesuai dengan penelitian sebelumnya tentang kandungan $\mathrm{CO}$ dari gas pembakaran batu bara dan Olive cake [13].

Penambahan biomassa dalam campuran menurunkan kadar NOx sesuai dengan penelitian sebelumnya [2]. Sebagaimana diketahui bahwa NOx cenderung terbentuk pada reaksi pembakaran pada temperatur tinggi. Semakin tinggi temperatur dalam gas pembakaran, maka NOx akan meningkat [15]. Prediksi NOx lebih dari 7000 ppm hasil simulasi ini masih jauh lebih tinggi dibandingkan dengan kenyataan sebesar 300 ppm. Model RGibbs untuk pembakaran, pada awalnya menghasilkan rekasi pembakaran dengan temperatur gas yang tinggi sehingga NOx yang dihasilkan terlalu tinggi. Pada sisi lain, dengan penambahan biomassa dan excess air, temperatur pembakaran menurun dan akan berakibat pada menurunnnya kadar NOx dalam gas pembakaran.

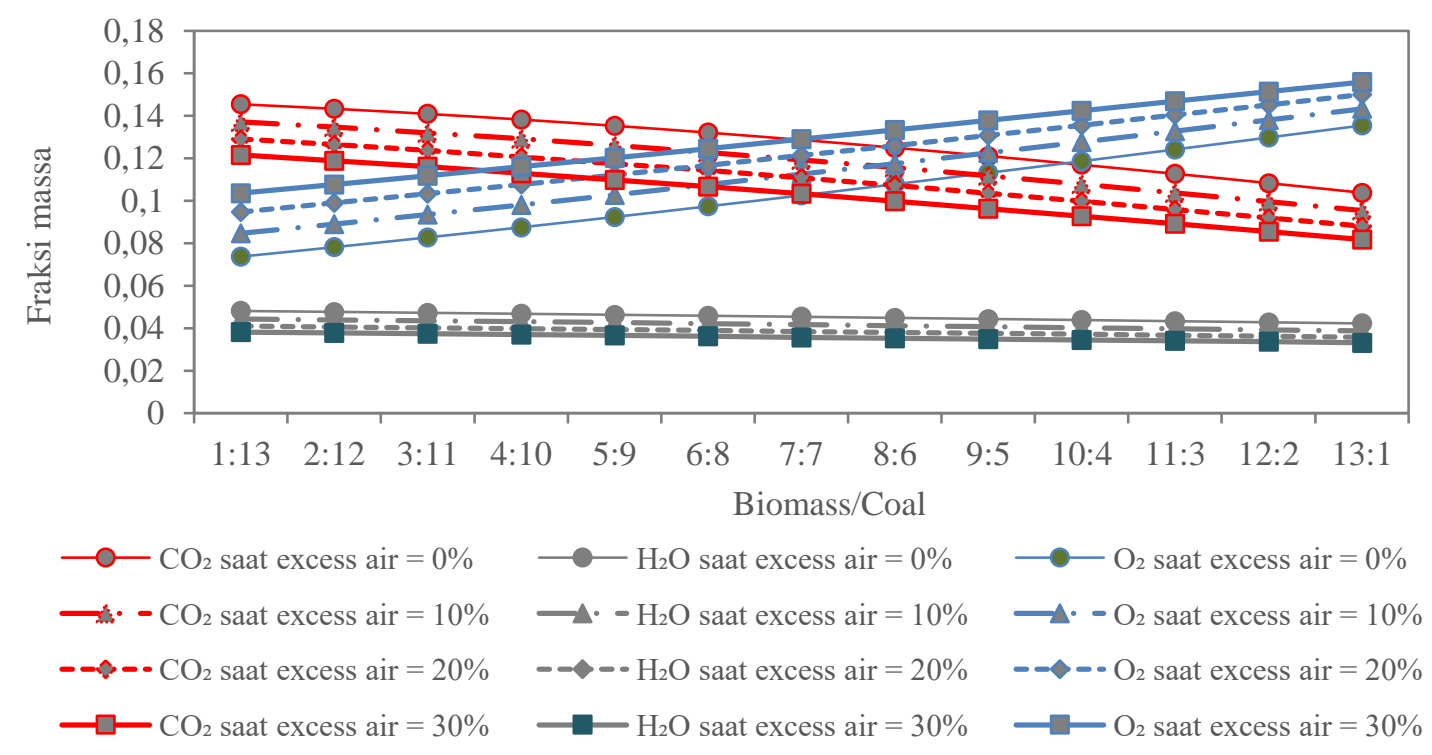

Gambar 4. Komposisi $\mathrm{CO}_{2}, \mathrm{H}_{2} \mathrm{O}$, dan $\mathrm{O}_{2}$ dalam gas hasil pembakaran 

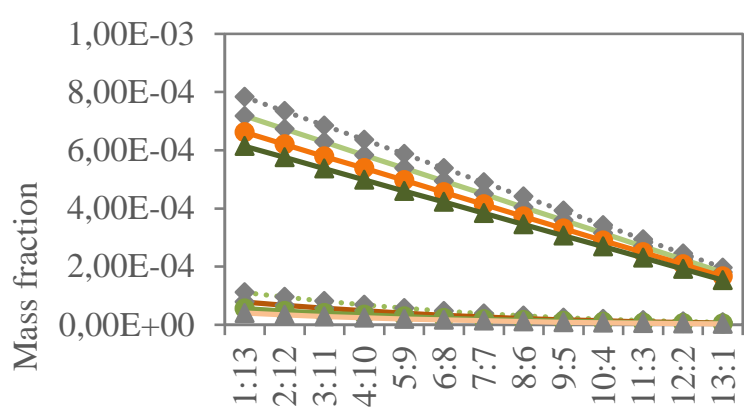

Biomass/Coal

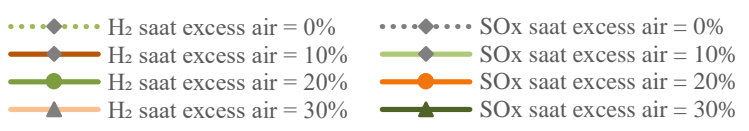

Gambar 5. Komposisi $\mathrm{H}_{2}$ dan SOx dalam gas hasil pembakaran

Kadar $\mathrm{H}_{2}$ dan SOx dalam gas pembakaran sebagaimana dapat dilihat pada Gambar 5, konsentrasinya kecil. Menurunnya kadar SOx seiring dengan penambahan biomassa karena kadar sulfur dalam biomassa yang lebih rendah dibandingkan dengan kadar sulfur dalam batu bara. Salah satu ciri dari gas pembakaran batu bara adalah adanya $\mathrm{SO}_{2}$. Sulfur dalam batu bara utamanya berada dalam fasa pyrite, thiopene, dan thiols dan hampir semua sulfur tersebut diubah menjadi $\mathrm{SO}_{2}$ (g) pada kondisi pembakaran miskin [16]. Hasil simulasi ini sejalan juga dengan studi sebelumnya yang menyatakan bahwa semakin tinggi temperatur menyebabkan $\mathrm{SO}_{2}$ mengalami peningkatan [16].

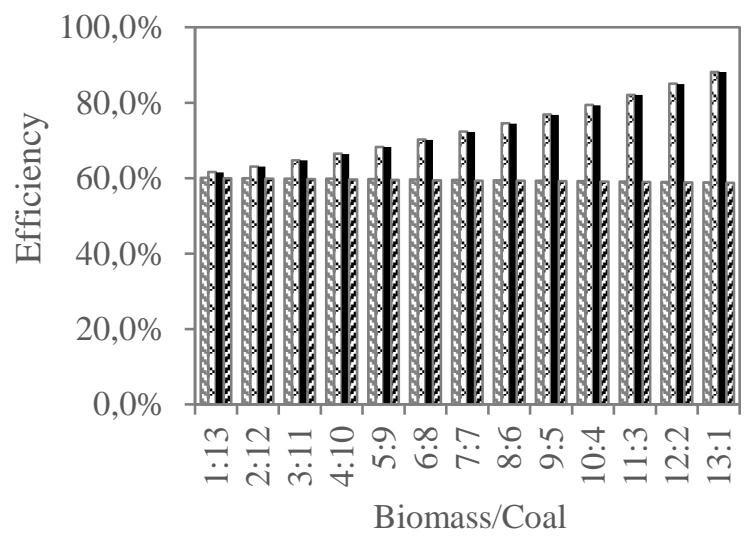

Efficiency at excess air 0\% $\quad$ Efficiency at excess air $10 \%$

- Efficiency at excess air 20\% घEfficiency at excess air 30\%

Gambar 6. Efisiensi pembakaran
Gambar 6 menunjukkan efisiensi pembakaran bersama biomassa dan batu bara. Secara umum, efisiensi pembakaran di atas $60 \%$. Semakin besar penambahan biomassa mampu meningkatkan efisiensi pembakaran pada excess air 10 dan 20\%, sedangkan pada excess air 0 dan $30 \%$, penambahan biomassa tidak berpengaruh pada efisiensi pembakaran. Penambahan biomassa, walaupun menurunkan temperatur pembakaran yang berarti turun juga jumlah energi yang dihasilkan, tetapi karena dibagi dengan energi input yang sedikit lebih rendah menyebabkan efisiensi pembakaran total meningkat. Pada excess air 30\%, sejumlah energi yang dihasilkan juga digunakan untuk pemanasan udara yang tidak ikut terbakar. Dalam hal ini, nitrogen dan oksigen yang tidak ikut bereaksi mengambil energi dan dibuang bersama gas buang.

\section{KESIMPULAN}

Pemodelan pembakaran bersama antara biomassa dan batu bara telah berhasil dilakukan dengan menggunakan ASPEN PLUS dan hasilnya tidak jauh berbeda dengan hasil dari eksperimen. Komposisi biomassa dan batu bara sangat berpengaruh pada temperatur gas, komposisi gas, dan efisiensi pembakaran. Rasio biomassa/udara yang semakin besar menyebabkan temperatur menurun dan efisiensi yang meningkat. Temperatur gas pembakaran yang tinggi menyebabkan kadar $\mathrm{NO}, \mathrm{CO}_{2}$ dan $\mathrm{SO}_{2}$ mengalami peningkatan.

\section{UCAPAN TERIMA KASIH}

Para penulis mengucapkan terima kasih kepada UNS atas fasilitasi pendanaan riset PNBP UNS tahun 2020.

\section{REFERENSI}

[1] C. P. Mahandari, "Fenomena flame lift-up pada pembakaran premixed gas propana," Universitas Indonesia. Fakultas Teknik, 2010.

[2] N. Maciejończyk, G. Pełka, W. Luboń, and D. Malik, "Analysis of the Flue Gas Produced During the Coal and Biomass Co-combustion in 
a Solid Fuel Boiler," Cham, pp. 239-246: Springer International Publishing, 2020.

[3] T. L. Yelverton et al., "Characterization of emissions from a pilot-scale combustor operating on coal blended with woody biomass," vol. 264, p. 116774, 2020.

[4] M. Issac, A. De Girolamo, B. Dai, T. Hosseini, and L. J. J. o. t. E. I. Zhang, "Influence of biomass blends on the particle temperature and burnout characteristics during oxy-fuel cocombustion of coal," Journal of the Energy Institute, vol. 93, no. 1, pp. 1-14, 2020.

[5] I. G. Wiratmaja, "Analisa Unjuk Kerja Motor Bensin Akibat Pemakaian Biogasoline," Jurnal Energi Dan Manufaktur, 2010.

[6] A. Khuriati, P. Purwanto, H. S. Huboyo, S. Suryono, and A. B. Putro, "Application of aspen plus for municipal solid waste plasma gasification simulation: case study of Jatibarang Landfill in Semarang Indonesia," in Journal of Physics: Conference Series, vol. 1025, no. 1, p. 012006: IOP Publishing, 2018.

[7] T. Unchaisri, S. Fukuda, A. Phongphipat, S. Saetia, and B. J. I. E. J. Sajjakulnukit, "Experimental Study on Combustion Characteristics in a CFB during Co-firing of Coal with Biomass Pellets in Thailand," vol. 19, no. 2, 2019.

[8] X. Zhang, M. Xu, R. Sun, and L. Sun, "Study on biomass pyrolysis kinetics," 2006.

[9] S. Suyitno and F. Lettner, "CFD-Modelling of External Heated Pyrolysis of Wood Chips," in 14th European Conference \& Exhibition: Biomass for Energy, Industry and Climate Protection, 2005.

[10] S. Suyitno, F. Lettner, H. L. Timmerer, and P. Haselbacher, "Devolatilisation in Biomass Pyrolysis: Influence of solid size, Moisture content, and Heat Radiation," in International Energy Conference, 2005.

[11] R. Radmanesh, Y. Courbariaux, J. Chaouki, and C. J. F. Guy, "A unified lumped approach in kinetic modeling of biomass pyrolysis," vol. 85, no. 9, pp. 1211-1220, 2006.

[12] Z. Arifin and S. Pranolo, "The Effect of Biogas Pressure in the Performance and Emission of Spark Ignition Engine," in IOP Conference Series: Materials Science and Engineering, vol. 694, no. 1, p. 012022: IOP Publishing, 2019.

[13] A. T. Atimtay and M. J. F. Varol, "Investigation of co-combustion of coal and olive cake in a bubbling fluidized bed with secondary air injection," vol. 88, no. 6, pp. 1000-1008, 2009.

[14] C. Chen, Q. N. Chan, P. R. Medwell, and G. Heng Yeoh, "Co-Combustion Characteristics and Kinetics of Microalgae Chlorella Vulgaris and Coal through TGA," Combustion Science and Technology, vol. 192, no. 1, pp. 26-45, 2020.

[15] Z. Xue, Z. Zhong, and X. Lai, "Investigation on gaseous pollutants emissions during cocombustion of coal and wheat straw in a fluidized bed combustor," Chemosphere, vol. 240, p. 124853, 2020.

[16] F. Kazanc, R. Khatami, P. Manoel Crnkovic, Y. A. J. E. Levendis, and fuels, "Emissions of NO x and SO2 from Coals of Various Ranks, Bagasse, and Coal-Bagasse Blends Burning in O2/N2 and O2/CO2 Environments," vol. 25, no. 7, pp. 28502861, 2011. 